\title{
Oral Zinc supplementation in the treatment of sepsis in Nepalese children: A double-blind randomised placebo- controlled trial

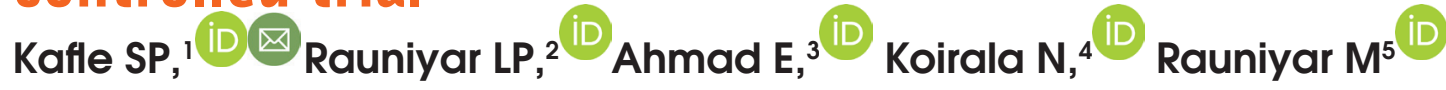

'Shyam Prasad Kafle, Assistant Professor, Department of Paediatrics and Adolescent Medicine, B.P. Koirala Institute of Health Sciences, Dharan, Sunsari, Nepal; '2alan Prasad Rauniyar, Consultant Paediatrician, Gajendra Narayan Singh Sagarmatha Zonal Hospital, Rajbiraj, Saptari, Nepal; ${ }^{3}$ Eqtedar Ahmad, Senior Resident, All India Institute of Medical Sciences, Patna, Bihar, India; ${ }^{4}$ Namu Koirala, Assistant Professor, Purbanchal University School of Health Sciences, Gothgaun, Morang, Nepal; ${ }^{5}$ Maya Rouniyar, Medical Officer, Department of Paediatrics and Adolescent Medicine, B.P. Koirala Institute of Health Sciences, Dharan, Sunsari, Nepal.

\begin{abstract}
Background:Sepsis is one of the most common causes of morbidity and mortality in young children.Zinc supplementation has a preventive effect against diarrhoeal diseases and respiratory infections, but little is known about its effect on the treatment of sepsis.

Objectives: To evaluate the benefit of oral Zinc supplementation along with standard antimicrobial therapy in childhood sepsis.

Methods: A randomised, double-blind placebo controlled trial was conducted on 164 septic children between 1-15 years of age from $15^{\text {th }}$ April 2017 to $14^{\text {th }}$ April 2018 in eastern Nepal tertiary care centre. Block randomisation was done with four participants in each block. There were 21 and 20 blocks in intervention and in placebo group respectively. Each child received oral zinc (20 mg elemental zinc/day) or a placebo once-daily for 14 days. Percentage was calculated for descriptive statistics and Chi-square for inferential statistics with $95 \% \mathrm{Cl}$ and $\mathrm{p}<0.05$ for data analysis using SPSS v. 16 . Results: Of the participants, $84(51.21 \%)$ received Zinc and $80(48.79 \%)$ received a placebo in adjunct to the standard antimicrobial therapy. Most of the children 76 (46.34\%) were under five years and were male 98 (59.75\%), and 69 (42.07\%) were underweight. Those receiving zinc and placebo had similar improvements at discharge; there was no reduction in the need for higher-order antibiotics or in the length of PICU/ hospital stay. Zinc supplementation in childhood sepsis had no benefit on decreasing mortality or decreasing severity $(p>0.05)$.

Conclusion: Zinc supplementation during childhood sepsis does not help in short-term clinical recovery.
\end{abstract}

Key words: Child; Sepsis; Zinc.

Access this article online

Website: www.jkmc.com.np

DOI: https://doi.org/10.3126/jkmc.v10i2.40019

HOW TO CITE

Kafle SP, Rauniyar LP, Ahmad E, Koirala N, Rauniyar M. Oral Zinc supplementation in the treatment of sepsis in Nepalese children: A double-blind randomised placebo-controlled trial. J Kathmandu Med Coll. 2021;10(2):84-91.

Address for correspondence

Dr. Shyam Prasad Kafle

Assistant Professor,

Department of Paediatrics and Adolescent Medicine,

B. P. Koirala Institute of Health Sciences,

Dharan, Sunsari, Province 1, Nepal

E-mail: kafle.shyam11@gmail.com

Copyright $\odot 2021$ Journal of Kathmandu Medical College (JKMC)

ISSN: 2019-1785 (Print), 2091-1793 (Online)

(C) (7) (2) This work is licensed under a Creative Commons Attribution-Non Commercial 4.0 International License.

\section{INTRODUCTION}

epsis is the systemic inflammatory response $\checkmark$ syndrome (SIRS) in the presence of a suspected or proven infection..$^{1-3}$ Majority of annual deaths in children under five years of age in developing countries are secondary to sepsis which accounts for about 7.5 million deaths. ${ }^{4}$ Thus, coming up with new interventions which can significantly improve the outcome of sepsis in children is an important step in reducing mortality.

Zinc is an essential micronutrient which is very crucial for the optimum development and function of cellmediated innate immunity, neutrophils, and natural killer (NK) cells. Phagocytosis, intracellular killing, and cytokine production all are affected by zinc deficiency. Along with them, the ability of zinc to function as an antioxidant and stabilise membranes, suggests that it 
has a role in the prevention of free radical-induced injury during inflammatory processes..$^{5-8}$

Zinc deficiency is common in developing countries where zinc supplementation has been studied extensively in many childhood conditions. ${ }^{9-12}$ Studies have shown that zinc supplementation reduces the incidence of childhood acute lower respiratory infection (ALRI). ${ }^{13-17}$ The present study is aimed to evaluate the benefit of oral Zinc supplementation along with standard antimicrobial therapy in childhood sepsis on decreasing mortality or decreasing severity.

\section{METHODOLOGY}

A randomised double-blind placebo-controlled trial was undertaken from 15th April 2017 to 14th April 2018 in the Department of Paediatrics and Adolescent Medicine at B.P. Koirala Institute of Health Sciences (BPKIHS), Dharan, Sunsari, Nepal. The participants and the researchers were blinded so that the intervention that each participant received was not known to both the participants as well as the investigators until the trial was over. A total of 164 septic children (84 in the intervention group and 80 in the placebo group) of age one to 15 years admitted in the department during the study period meeting the inclusion criteria were enrolled in the study (Figure 1). All children admitted to paediatrics ward/paediatric intensive care unit (PICU) with the diagnosis of sepsis and whose parents gave informed written consent for the study were the subjects for the study. Sampling was done using census sampling method. Children whose parents declined the informed written consent, or, who were immune-compromised or, who had an inborn error of metabolism were excluded from the study. Children admitted with the diagnosis of sepsis and managed with oral zinc along with the standard antimicrobial protocol were the subjects in the interventional group. Children with the diagnosis of sepsis and managed with the standard antimicrobial therapy receiving placebo were the subjects in the control group. Ethical clearance was obtained from the Institutional Review Committee of BPKIHS (Ref. 0867/016). Block randomisation was done into the two treatment groups (intervention and the placebo) where participants in each block were four and there were altogether 41 blocks ( 21 in the intervention group and 20 in the placebo group).

After obtaining informed written consent from parents, relevant history including age, gender, weight, Body mass index (BMI) were recorded in a preset proforma. Height was measured by using the stadiometer (Seca). Subjects were made to stand without shoes, their heels, buttocks, and back touching the wall with eyes looking straight forward in the Frankfurt plane and the bi-auricular plane horizontal. A steel ruler was kept firmly over the vertex horizontally to measure the height. Weight was measured by a digital weighing machine in light clothing, with a minimum precision of $10 \mathrm{gm}$. The weighing scale was corrected for any zeroerror before every measurement. BMI was calculated by the formula: $\mathrm{BMI}=$ weight $(\mathrm{kg}) /$ height $(\mathrm{m})^{2}$.

Essential investigations were sent. Each child was assigned a patient identification code in the given block and was allocated to receive the drug depending upon the treatment specified in the sealed envelope. Drug coding was done by the pharmaceutical company itself. After completion of the data collection, the drug codes were decoded based on information provided by the pharmaceutical company. If the patient was discharged before completing 14 days of intervention therapy, the patient was asked to take it for a total of 14 days once daily at home and was followed up and re-evaluated at the outpatient department (OPD), though follow-ups at OPD are not mentioned in the study. In the drug group, each subject received elemental zinc $20 \mathrm{mg} /$ day (formulation: zinc sulphate dispersible tablets of $20 \mathrm{mg}$ ) once daily for 14 days along with standard antimicrobial therapy; Whereas in the placebo group each subject received placebo tablets similar to the zinc formulation once daily for 14 days along with standard antimicrobial therapy. No specific name was given to the placebo tablets as both the zinc and placebo tablets were provided in the sealed envelope by the pharmaceutical company. Drug coding was done by the pharmaceutical company itself. After completion of the data collection the drug code was decoded based on information provided by the pharmaceutical company. In the interventional group minor side effects such as vomiting and gastric upset were expected in a few cases which was explained prior to the intervention.

Outcome measures were taken in terms of survival, reduction in length of hospital stay, need of higher-order antibiotics, need of blood component transfusion and duration of mechanical ventilation.

Collected data were entered in Microsoft Excel Sheet 2010 and were converted into Statistical Package for Social Sciences for Statistical analysis (SPSS) Statistics for Windows, version 16.0 (SPSS Inc., Chicago, Ill., USA). For descriptive statistics, percentage was calculated along with the tabular presentation. For inferential statistics Chi-square test was applied to find out the significant differences between the groups with the related variable at $95 \% \mathrm{Cl}$ where $\mathrm{p}<0.05$. 


\section{RESULTS}

Of the children enrolled in the trial, 84 received zinc, and 80 received placebo. The study enrolled 76 children belonging to the age group 1-5 years. Of the 164 children, 98 (59.75\%) were male and 66 (40.25\%) were female. As per BMI, 69 (42.07\%) were underweight, 91 (57.93\%) had normal BMI, three (1.82\%) were overweight, and one $(0.61 \%)$ was obese.

Out of 164 children enrolled in the study, 114 (69.09\%) had SOFA score $<2$ and 50 (30.48\%) had the SOFA score of $\geq 2$. In 61 (37.19\%) children with sepsis the primary source of infection was the respiratory system. Zinc supplementation was well-tolerated, and no adverse events were reported (Table 1).

The baseline characteristics of the two study groups were comparable to each other, and there was no significant difference between the two study groups based on the baseline characteristics (Table 2).

The use of zinc neither reduced the need for higher-order antibiotics nor decreased the need for blood component transfusion with the increase in the severity of the sepsis. No death was recorded among the study population. Those receiving zinc and placebo were considered similar in terms of improvement at discharge even with variable degrees of sepsis severity (Table 3 ).

There was no significant association between the use of zinc and reduction in the length of hospital stay even with the increase in the severity of sepsis (Table 4).

There was no significant association between the use of zinc and the duration of PICU stay or paediatric ward stay or requirement of mechanical ventilation (Table 5).

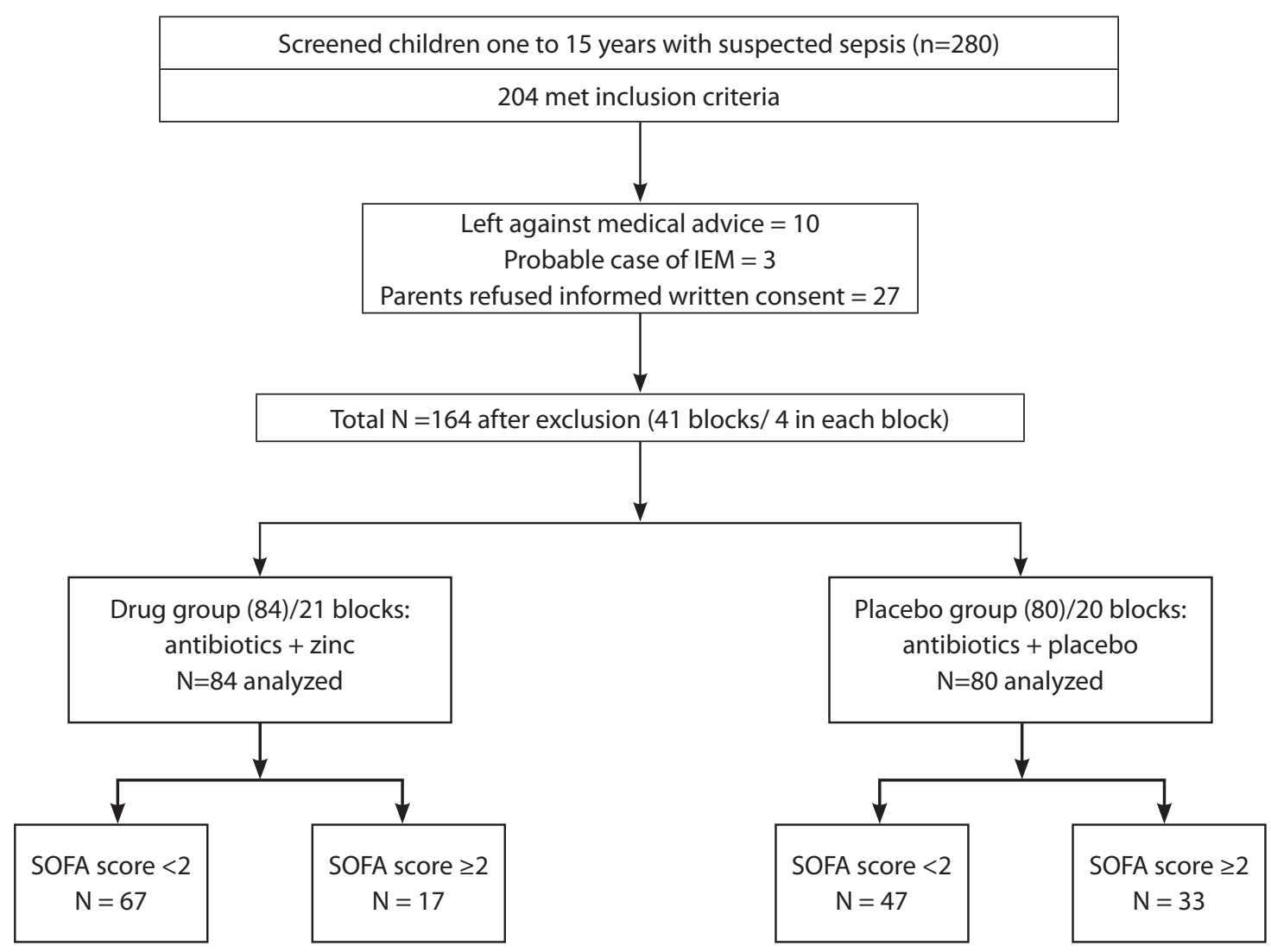

(IEM = inborn error of metabolism)

Figure 1: Study design 
Table 1: Baseline characteristics $(\mathrm{N}=164)$

\begin{tabular}{|c|c|c|c|}
\hline \multirow{2}{*}{ Characteristics } & \multirow{2}{*}{ Categories } & \multicolumn{2}{|c|}{ No. of Children (Percentage) } \\
\hline & & Zinc: $n=84(51.22)$ & Placebo: $n=80(48.78)$ \\
\hline \multirow{3}{*}{ Age (years) } & $1-5$ & $42(25.61)$ & $34(20.73)$ \\
\hline & $6-10$ & $23(14.02)$ & $28(17.07)$ \\
\hline & $11-15$ & $19(11.59)$ & $18(10.98)$ \\
\hline \multirow{2}{*}{ Gender } & Male & $51(31.09)$ & $47(28.65)$ \\
\hline & Female & $33(20.12)$ & $33(20.12)$ \\
\hline \multirow{5}{*}{ Residence (districts) } & Sunsari & $27(16.46)$ & $22(13.41)$ \\
\hline & Morang & $18(10.98)$ & $13(7.92)$ \\
\hline & Jhapa & $12(7.31)$ & $8(4.88)$ \\
\hline & Saptari & $10(6.09)$ & $10(6.09)$ \\
\hline & Others & $17(10.36)$ & $27(16.46)$ \\
\hline \multirow{3}{*}{ Religion } & Hindu & $60(36.58)$ & $53(32.32)$ \\
\hline & Kirat & $18(10.98)$ & $21(12.80)$ \\
\hline & Muslim & $6(3.66)$ & $6(3.66)$ \\
\hline \multirow{4}{*}{ BMI } & $<5^{\text {th }}$ percentile & $37(22.56)$ & $32(19.51)$ \\
\hline & $5^{\text {th }}-<85^{\text {th }}$ percentile & $45(27.43)$ & $46(28.05)$ \\
\hline & $85^{\text {th }}-<95^{\text {th }}$ percentile & $2(1.22)$ & $1(0.61)$ \\
\hline & $\geq 95^{\text {th }}$ percentile & - & $1(0.61)$ \\
\hline \multirow{2}{*}{ Sepsis severity (SOFA) score } & $<2$ & $67(40.85)$ & $47(28.65)$ \\
\hline & $\geq 2$ & $17(10.36)$ & $33(20.12)$ \\
\hline \multirow{6}{*}{ Primary source of infection (system) } & Respiratory & $32(19.51)$ & $29(17.68)$ \\
\hline & Gastrointestinal & $29(17.68)$ & $24(14.63)$ \\
\hline & Genitourinary diseases & $12(7.31)$ & $14(8.53)$ \\
\hline & Cardiovascular & $8(4.87)$ & $6(3.66)$ \\
\hline & Central nervous System & $3(1.82)$ & $5(3.04)$ \\
\hline & Others & $2(1.22)$ & - \\
\hline
\end{tabular}

$\mathrm{BMI}=$ body mass index $=$ weight in $\mathrm{kg} /(\text { height in } \mathrm{m})^{2}$

Table 2: Association between study groups and baseline characteristics $(\mathbf{N}=164)$

\begin{tabular}{|c|c|c|c|c|}
\hline \multirow{2}{*}{ Variables } & \multirow{2}{*}{ Category } & \multicolumn{2}{|c|}{ No. of children (Percentage) } & \multirow{2}{*}{ p-value } \\
\hline & & Zinc & Placebo & \\
\hline \multirow{3}{*}{ Age (years) } & $1-5$ & $42(25.69)$ & $34(20.73)$ & \multirow{3}{*}{$0.532^{*}$} \\
\hline & $6-10$ & $23(14.02)$ & $28(17.07)$ & \\
\hline & $11-15$ & $19(11.58)$ & $18(10.97)$ & \\
\hline \multirow{2}{*}{ Gender } & Male & $51(31.09)$ & $47(28.65)$ & \multirow{2}{*}{$0.798^{*}$} \\
\hline & Female & $33(20.12)$ & $33(20.12)$ & \\
\hline \multirow{5}{*}{ Residence } & Sunsari & $27(16.46)$ & $22(13.41)$ & \multirow{5}{*}{$0.368^{*}$} \\
\hline & Morang & $18(10.97)$ & $13(7.92)$ & \\
\hline & Jhapa & $12(7.31)$ & $8(4.87)$ & \\
\hline & Saptari & $10(6.09)$ & $10(6.09)$ & \\
\hline & Others & $17(10.36)$ & $27(16.46)$ & \\
\hline \multirow{3}{*}{ Religion } & Hindu & $60(36.58)$ & $53(32.31)$ & \multirow{3}{*}{$0.753^{*}$} \\
\hline & Kirat & $18(10.97)$ & $21(12.80)$ & \\
\hline & Muslim & $6(3.65)$ & $6(3.65)$ & \\
\hline \multirow{4}{*}{ BMI } & $<5^{\text {th }}$ percentile & $37(22.56)$ & $32(19.51)$ & \multirow{4}{*}{$0.572 \dagger$} \\
\hline & $5^{\text {th }}-<85^{\text {th }}$ percentile & $45(27.43)$ & $46(28.04)$ & \\
\hline & $85^{\text {th }}-<95^{\text {th }}$ percentile & $2(1.21)$ & $1(0.60)$ & \\
\hline & $\geq 95^{\text {th }}$ percentile & - & $1(0.60)$ & \\
\hline
\end{tabular}

Test used: *Chi-square; +Fisher Exact test; $\mathrm{p}<0.05$ 
Table 3: Association of zinc with need of higher order antibiotics, requirement of blood transfusion and survival at discharge with sepsis severity $(\mathrm{N}=164)$

\begin{tabular}{|c|c|c|c|c|}
\hline \multirow{2}{*}{ SOFA score } & \multirow{2}{*}{ Drug } & \multicolumn{2}{|c|}{ No. (\%) receiving treatment } & \multirow{2}{*}{ p-value } \\
\hline & & Yes & No & \\
\hline \multicolumn{5}{|c|}{ Requirement of higher order antibiotics } \\
\hline \multirow{2}{*}{$<2$} & Zinc & $24(14.63)$ & $43(26.21)$ & \multirow{2}{*}{0.787} \\
\hline & Placebo & $18(10.97)$ & $29(17.68)$ & \\
\hline \multirow{2}{*}{$\geq 2$} & Zinc & $10(6.09)$ & $7(4.26)$ & \multirow{2}{*}{0.903} \\
\hline & Placebo & $20(12.19)$ & $13(7.92)$ & \\
\hline \multirow{2}{*}{ Total } & Zinc & $34(20.73)$ & $50(30.48)$ & \multirow{2}{*}{0.365} \\
\hline & Placebo & $38(23.17)$ & $42(25.60)$ & \\
\hline \multicolumn{5}{|c|}{ Requirement of blood component transfusion } \\
\hline \multirow{2}{*}{$<2$} & Zinc & - & $67(40.85)$ & \multirow{2}{*}{-} \\
\hline & Placebo & - & $47(28.65)$ & \\
\hline \multirow{2}{*}{$\geq 2$} & Zinc & $1(0.60)$ & $16(9.75)$ & \multirow{2}{*}{0.980} \\
\hline & Placebo & $2(1.21)$ & $31(18.90)$ & \\
\hline \multirow{2}{*}{ Total } & Zinc & $1(0.60)$ & $83(50.60)$ & \multirow{2}{*}{0.528} \\
\hline & Placebo & $2(1.21)$ & 78 (47.56) & \\
\hline \multirow{2}{*}{ SOFA score } & \multicolumn{3}{|c|}{ Survival at discharge } & \\
\hline & Drug & Without disability & With disability & \\
\hline \multirow{2}{*}{$<2$} & Zinc & $65(39.63)$ & $2(1.21)$ & \multirow{2}{*}{0.232} \\
\hline & Placebo & $47(28.65)$ & - & \\
\hline \multirow{2}{*}{$\geq 2$} & Zinc & $13(7.92)$ & $4(2.43)$ & \multirow{2}{*}{0.774} \\
\hline & Placebo & 24 (14.63) & $9(5.48)$ & \\
\hline \multirow{2}{*}{ Total } & Zinc & 78 (47.56) & $6(3.65)$ & \multirow{2}{*}{0.362} \\
\hline & Placebo & 71 (43.29) & $9(5.48)$ & \\
\hline
\end{tabular}

Test used: Chi-square

Table 4: Association of zinc with sepsis severity and the total duration of hospital stay $(\mathrm{N}=164)$

\begin{tabular}{|c|c|c|c|c|c|}
\hline \multirow{2}{*}{ SOFA Score } & \multirow{2}{*}{ Drug } & \multicolumn{3}{|c|}{ Total length of hospital stays in days } & \multirow{2}{*}{ p-value } \\
\hline & & $<3$ & $3-6$ & $\geq 7$ & \\
\hline \multirow{2}{*}{$<2$} & Zinc & $1(0.60)$ & $51(31.09)$ & $15(9.14)$ & \multirow{2}{*}{0.317} \\
\hline & Placebo & $2(1.21)$ & $34(20.73)$ & $11(6.70)$ & \\
\hline \multirow{2}{*}{$\geq 2$} & Zinc & $1(0.60)$ & $7(4.26)$ & $9(5.48)$ & \multirow{2}{*}{0.653} \\
\hline & Placebo & - & $16(9.75)$ & $17(10.36)$ & \\
\hline \multirow{2}{*}{ Total } & Zinc & $2(1.21)$ & $58(35.36)$ & $24(14.63)$ & \multirow{2}{*}{0.669} \\
\hline & Placebo & $2(1.21)$ & $50(30.48)$ & $28(17.07)$ & \\
\hline
\end{tabular}

Test used: Chi-square

Table 5: Association of zinc with length of paediatric ward stay, length of PICU stay, and need of mechanical ventilation $(\mathrm{N}=164)$

\begin{tabular}{|c|c|c|c|c|}
\hline \multirow{2}{*}{ Drug } & \multicolumn{3}{|c|}{ Length of paediatric ward stay } & \multirow{2}{*}{ p-value } \\
\hline & $<3$ days & $3-<7$ days & $>7$ days & \\
\hline Zinc & $2(1.21)$ & $58(35.36)$ & $24(14.63)$ & \multirow{2}{*}{0.768} \\
\hline Placebo & $2(1.21)$ & $51(31.09)$ & $27(16.46)$ & \\
\hline \multicolumn{5}{|c|}{ Length of PICU stay } \\
\hline Drug & No PICU & $<3$ days & $3-<7$ days & \\
\hline Zinc & $83(50.60)$ & $1(0.60)$ & - & 0.396 \\
\hline Placebo & $77(46.95)$ & $2(1.21)$ & $1(0.60)$ & \\
\hline \multicolumn{5}{|c|}{ Need of mechanical ventilation } \\
\hline Drug & Yes & No & NA & \\
\hline Zinc & - & $84(51.21)$ & NA & 0.230 \\
\hline Placebo & $1(0.60)$ & $79(48.17)$ & NA & \\
\hline
\end{tabular}

Test used: Chi-square, NA- not applicable 


\section{DISCUSSION}

Sepsis is said to be one of the leading causes of death among children not only in developing countries but also in developed countries. Awareness is increasing on the patients surviving sepsis who often have longterm physical, psychological, and cognitive disabilities with significant health care and social implications. ${ }^{18-20}$ Also, there is a paucity of literature regarding the exact role of zinc in paediatric sepsis, a clear understanding of which would aid in designing such studies and the management protocol of paediatric sepsis.

In this study, the most common age group was 1-5 years comprising almost half of the children with sepsis. Males were predominant, comprising 98 (59.75\%) of the study population. The only study; Role of zinc in severe pneumonia: a randomised double-blind placebocontrolled study, by Shah et al. conducted at the same institute, showed that, in children below five years, $65 \%$ were male. ${ }^{21}$ Almost one-third were from the same district of Sunsari and more than two-thirds were Hindu by religion following Kirat and Muslim as accordance with the distribution of religion of the eastern part of Nepal. Of the study population, 91 (55.48\%) had normal BMI ( $5^{\text {th }}$ to $85^{\text {th }}$ percentile) and $69(42.07 \%)$ were underweight. In contrast, the Nepal Demographic and Health Survey (NDHS) 2016 in under-five children mentioned 27\% are underweight and 5\% are severely underweight (NDHS 2016). ${ }^{20}$ This study had a slightly greater number of underweight children. It could be because malnourished children are more prone to developing sepsis, which will not exactly report the incidence of undernutrition in the community.

In this study, the primary cause of childhood sepsis was the involvement of the respiratory system $(61,37.19 \%)$ followed by gastrointestinal (GI), genitourinary and central nervous system respectively. The marker of sepsis severity (SOFA score) in most cases $(114,69.09 \%)$ was $<2$. This could be because of the enrollment of cases from the paediatric ward also, which accounts for most of the admissions in the paediatric department. This study showed no significant benefit of Zinc supplementation in the treatment outcome of sepsis. Similar is the finding in the Shah et al. study conducted at the same institute. The study by Valentiner-Branth et al. conducted in the central part of Nepal showed that adjuvant zinc treatment in pneumonia among children 2-35 months of age had no benefit over standard treatment. ${ }^{21}$

Similar is the finding of zinc treatment in the study by Wadhwa et al. conducted in New Delhi with no beneficiary effect on zinc supplementation over standard antimicrobial therapy in severe pneumonia of 2-24 months of age..$^{23}$

On contrary to these findings the study conducted by Bhatnagar et al. showed that zinc supplementation has reduced treatment failure by $40 \%$ with probable serious bacterial infections. ${ }^{10}$ Other studies have also shown that Zinc as an adjunct therapy in the management of pneumonia has beneficial effects. ${ }^{13-15}$ But the study by Mehta et al. in the same institute showed, there is no decrease in treatment outcome in neonatal sepsis. ${ }^{24}$

The only significant beneficiary association found in young infants could be due to the low zinc level in human milk with the immature immune system as a result of severe sepsis. ${ }^{10}$

Both study groups are found to be similar, based on the need for blood transfusion with the increase in the severity of sepsis. Zinc supplementation statistically does not have a beneficiary effect in the reduction of the blood component therapy. Since only three children required blood transfusion, no further association could be analyzed in children with SOFA score $<2$. In this study, intervention in the zinc supplementation group does not show improved outcomes in terms of survival, or reduction in sepsis severity, or requirement of PICU admission, or need of mechanical ventilation over the placebo group. The overall PICU or ward stay is similar in both the groups however the hospital stay is longer in the severe sepsis group.

Majority of children with SOFA Score <2 (114, 69.09\%) had 3-7 days of hospital stay whereas, in the group with SOFA score $\geq 2$, the majority had a hospital stay of more than seven days.

In this study; only one child in the placebo group required mechanical ventilation for acute respiratory distress syndrome.

Similar to the above-mentioned studies; in this study, we have supplemented the children diagnosed with sepsis with $20 \mathrm{mg}$ elemental zinc. Though similar drug doses were used in this study compared to various trials, we had different outcomes because of the fact that we had not assessed the blood zinc level before or after the study.

Despite the similarity in baseline characteristics, the outcome of the study may vary. This is because the abovementioned studies are mostly done among age groups 
below five years but, this study was done among a wide range of population from age one to 15 years with a wide range of aetiology. Regarding other secondary outcomes like decrease in need of blood component transfusion or, the requirement of mechanical ventilation or, use of higher-order antibiotics could not be compared because of the nonavailability of other similar studies.

Bhutta et al. evaluated the prevention of diarrhoea and pneumonia by zinc supplementation in children in developing countries by pooling randomised controlled trials. ${ }^{25}$ The prevention of serious infectious morbidity through household visits was also evaluated and results showed substantial reductions in diarrhoea and pneumonia rates, the two leading causes of deaths in these settings. ${ }^{25}$ Zinc supplementation has been shown to reduce the incidence of childhood pneumonia, but its effect on the course of pneumonia when administered as an adjunct to antibiotic therapy is still unclear. Study sites and designs differ, particularly in the timing of zinc treatment and in determining recovery from pneumonia, which can explain the differences in study findings. ${ }^{26}$ Though we have considered the various cause of sepsis in this study, the outcome of zinc supplementation along with standard antimicrobial therapy should be evaluated separately as the cause of sepsis can be variable. Future studies are needed that are large enough to be sufficiently powered to accommodate various causes of sepsis and its outcome on zinc supplementation.

Possibly this is the first double-blinded randomised control trial using oral zinc supplementation in septic children conducted in a tertiary care centre of Eastern Nepal which is the only referral centre from neighbouring districts with adequate sample size and duration. Though there is a proven benefit of zinc supplementation in diarrhoea, the role of zinc in Paediatrics sepsis is still debatable.

\section{REFERENCES}

1. Goldstein B, Giroir B, Randolph A. International paediatrics sepsis consensus conference: Definitions for sepsis and organ dysfunction in Paediatrics. Pediatr Crit Care Med. 2005;6(1):2-8. [PubMed | Full Text | DOI]

2. Weiss SL, Peters MJ, Alhazzani W, Agus MSD, Flori $H R$, Inwald DP, et al. Surviving sepsis campaign international guidelines for the management of septic shock and sepsis-associated organ dysfunction in children. Paediatr Crit Care Med. 2020;2(21):e52-e106. [PubMed | Full Text | DOI]
There were some limitations to this study. The preintervention zinc level is unknown and most of the patients were in the less severe sepsis category. This study evaluated a diverse population with diverse aetiology for sepsis as a whole, so beneficial effects on certain conditions might have been overlooked.

\section{CONCLUSION}

The use of oral zinc supplementation as an adjunct to standard antimicrobial therapy in children with sepsis did not show any clinical benefit on survival outcome at discharge. With the zinc supplementation, there was no reduction in the need for the higher-order antibiotics or blood transfusion, or mechanical ventilation, or the length of hospital, or PICU stay. Therefore, zinc supplementation during sepsis neither helped in shortterm clinical recovery nor helped in the reduction of higher-order antibiotics or requirement of blood transfusion. The most possible reason for not having the benefit of zinc supplementation in sepsis could be because of the enrollment of the majority of patients with less severe sepsis. Possibly to document zinc could have a beneficial effect on severe septic patients, further similar studies are required mainly comprising intensive care unit (ICU) patients.

\section{ACKNOWLEDGEMENTS}

The authors would like to acknowledge Mr. D. D. Baral, from the school of public health, BPKIHS for his help in the statistical analysis as well as Deurali Janta Pharmaceuticals Limited, Nepal for providing the Zinc and the placebo tablets used in the study. There were no competing interests in this study.

Conflict of interests: None

Source(s) of support: None

3. NICE. National Institute for Health and Care Excellence: Sepsis: recognition, diagnosis and early management (NICE Guideline 51). 2016. [PubMed | Full Text]

4. Wiens MO, Kumnakumba E, Kissoon, Ansermino JM, Ndamira A, Larson CP. Paediatrics sepsis in the developing world: challenges in defining sepsis and issues in post-discharge mortality. Clin Epidemiol. 2012;4:319-25. [PubMed | Full Text | DOI]

5. Shankar $A H$, Prasad AS. Zinc and immune function: the biological basis of altered resistance to infection. Am J Clin Nutr. 1998 Aug;68(2 Suppl):447S-463S. [PubMed | Full Text | DOI] 
6. Banupriya N, Kalaivani S, Benet Bosco D, Vishnu B. Zinc supplementation in paediatrics practice. J Pediatr Sci. 2015;7:e240. [Full Text | DOI]

7. Prasad AS. Clinical. Immunological, antiinflammatory and antioxidant roles of zinc. Exp Gerontology 2008; 43:370-7. [PubMed | Full Text | DOI]

8. Lazzerini $M$, Ronfani L. Oral zinc for treating diarrhoea in children. Cochrane Database Syst Rev. 2008 Jul 16;(3):CD005436. [PubMed | Full Text | DOI]

9. Bhatnagar S, Natchu UCM. Zinc in child health and disease. Indian J Pediatr. 2004;71:991-5. [PubMed | Full Text | DOI]

10. Bansal A, Parmar VR, Basu S, Kaur J, Jain S, Saha A, et al. Zinc supplementation in severe acute lower respiratory tract infection in children: a tripleblind randomized placebo controlled trial. Indian J Pediatr. 2011 Jan;78(1):33-7. [PubMed | Full Text | DOI]

11. Nepal AK, Gelal B, Mehta K, Lamsal M, Pokharel PK, Baral N. Plasma zinc levels, anthropometric and socio-demographic characteristics of school children in eastern Nepal. BMC Res Notes. 2014 Jan 9;7:18. [PubMed | Full Text | DOI]

12. Roth DE, Richard SA, Black RE. Zinc supplementation for the prevention of acute lower respiratory infection in children in developing countries: metaanalysis and meta-regression of randomized trials. Int J Epidemiol. 2010; 39:795-808. [PubMed | Full Text | DOI]

13. Brooks WA, Yunus M, Santosham M, Wahed MA, Nahar K, Yeasmin S, et al. Zinc for severe pneumonia in very young children: Double-blind placebocontrolled trial. Lancet. 2004 May 22;363(9422):16838. [PubMed | Full Text | DOI]

14. Basnet $S$, Shrestha PS, Sharma A, Mathisen M, Prasai $\mathrm{R}$, Bhandari $\mathrm{N}$, et al. A randomized controlled trial of zinc as adjuvant therapy for severe pneumonia in young children. Pediatrics. 2012 Apr;129(4):701-8. [PubMed | Full Text | DOI]

15. Chang $A B$, Torzillo PJ, Boyce NC, White AV, Stewart PM, Wheaton GR, et al. Zinc and vitamin A supplementation in indigenous Australian children hospitalized with lower respiratory tract infection: a randomised controlled trial. Med J Aust. 2006 Feb 6;184(3):107-12. [PubMed | Full Text | DOI]

16. Dellinger RP, Levy MM, Rhodes A, Annane D, Gerlach $\mathrm{H}$, Opal SM, et al. Surviving sepsis campaign: International guidelines for management of severe sepsis and septic shock: 2012. Crit Care Med. 2013 Feb;41(2):580-637. [PubMed | Full Text | DOI]

17. Rhodes A, Evans LE, Alhazzani W, Levy MM, Antoneli $M$, Ferrer $R$, et al. Surviving sepsis campaign:
International guidelines for management of sepsis and septic shock: 2016. Crit Care Med. 2017 Mar;45(3):486-552. [PubMed | Full Text | DOI]

18. Vincent JL, de Mendonça A, Cantraine F, Moreno R, Takala J, Suter PM, et al. Use of the SOFA score to assess the incidence of organ dysfunction/failure in intensive care units: results of a multicenter, prospective study. Working group on "sepsis-related problems" of the European Society of Intensive Care Medicine. Crit Care Med. 1998 Nov;26(11):1793-800. [PubMed | Full Text | DOI]

19. Iwashyna TJ, Ely EW, Smith DM, Langa KM. Longterm cognitive impairment and functional disability among survivors of severe sepsis. JAMA. 2010 Oct 27;304(16):1787-94. [PubMed | Full Text | DOI]

20. Ministry of Health, Nepal; New ERA; and ICF. 2017. Nepal Demographic and Health Survey 2016. Kathmandu, Nepal: Ministry of Health, Nepal. [FullText]

21. Valentiner-Branth $P$, Shrestha PS, Chandyo RK, Mathisen M, Basnet S, Bhandari N, et al. A randomized controlled trial of the effect of zinc as adjuvant therapy in children 2-35 mo of age with severe or non severe pneumonia in Bhaktapur, Nepal. Am J Clin Nutr. 2010 Jun;91(6):1667-74. [PubMed | Full Text | DOI]

22. Shah GS, Dutta AK, Shah D, Mishra OP. Role of zinc in severe pneumonia: A randomized double bind placebo-controlled study. Ital J Pediatr. 2012;8:36. [PubMed | Full Text | DOI]

23. Wadhwa N, Chandran A, Aneja S, Lodha R, Kabra SK, Chaturvedi MK, et al. Efficacy of zinc given as an adjunct in the treatment of severe and very severe pneumonia in hospitalized children 2-24 mo of age: a randomized, double-blind, placebo-controlled trial. Am J Clin Nutr. 2013 Jun;97(6):1387-94. [PubMed | Full Text | DOI]

24. Mehta K, Bhatta NK, Majhi S, Shrivastava MK, Singh RR. Oral Zinc supplementation for reducing mortality in probable neonatal sepsis: A double blind randomized placebo-controlled trial. Indian Pediatr. 2013; 50:390-3. [PubMed | Full Text | DOI]

25. Bhutta ZA, Black RE, Brown KH, Gardner JM, Gore $S$, Hidayat A. (Zinc Investigator/ Collaborative Group). Prevention of diarrhoea and pneumonia by zinc supplementation in children in developing countries: Pooled analysis of randomized controlled trials. J Pediatr. 1999;135:689-97. [PubMed | Full Text | DOI]

26. Chandra U, Natchu, M, Fataki MR, Fawzi WW. Zinc as an adjunct for childhood pneumonia - interpreting early results. Nutrition Reviews Vol. 66(7):398-405. [PubMed | Full Text | DOI] 